\title{
Common Fixed Points of a Countable Family of I- Nonexpansive Multivalued Mappings in Banach Spaces
}

\author{
Poonam Lata Sagar ${ }^{1, *}$, S.K. Malhotra ${ }^{2}$ \\ ${ }^{1}$ Samrat Ashok Technological Institute, Vidisha (M.P.) India \\ ${ }^{2}$ M.P. Professional Board of Examination, Bhopal (M.P.) India \\ *Corresponding author: poonamlata.sagar@gmail.com
}

Received April 24, 2014; Revised August 01, 2014; Accepted August 12, 2014

\begin{abstract}
In this paper, we introduce a modified Ishikawa iteration for a countable family of multi-valued mappings. We use the best approximation operator to obtain weak and strong convergence theorems in a Banach space. We apply the main results to the problem of finding a common fixed point of a countable family of INonexpansive multi-valued mappings.
\end{abstract}

Keywords: I-Nonexpansive multi-valued mapping, fixed point, weak convergence, strong convergence, Banach space, Ishikawa iteration

Cite This Article: Poonam Lata Sagar, and S.K. Malhotra, "Common Fixed Points of a Countable Family of I-Nonexpansive Multivalued Mappings in Banach Spaces." American Journal of Applied Mathematics and Statistics, vol. 2, no. 4 (2014): 239-243. doi: 10.12691/ajams-2-4-12.

\section{Introduction}

Let $\mathrm{D}$ be a nonempty and convex subset of a Banach spaces $\mathrm{E}$. The set $\mathrm{D}$ is called proximinal if for each $\mathrm{x} \in \mathrm{E}$, there exists an element $y \in D$ such that $\|x-y\|=d(x, D)$, where $d(x, D)=\inf \{\|x-z\|: z \in D\}$. Let $C B(D), C C B(D)$, $K(D)$ and $P(D)$ denote the families of nonempty closed bounded subsets, nonempty closed convex bounded subsets, nonempty compact subsets, and nonempty proximinal bounded subsets of $\mathrm{D}$, respectively. The Hausdorff metric on $\mathrm{CB}(\mathrm{D})$ is defined by

$$
H(A, B)=\max \left\{\begin{array}{cc}
\sup d(x, B) & \sup d(y, A) \\
x \in A & x \in B
\end{array}\right\}
$$

for $\mathrm{A}, \mathrm{B} \in \mathrm{CB}(\mathrm{D})$. A single-valued map $\mathrm{T}: \mathrm{D} \rightarrow \mathrm{D}$ is called nonexpansive if $\left\|T_{x}-T_{y}\right\| \leq\|x-y\|$ for all $x, y \in D$. A multivalued mapping $T: D \rightarrow C B(D)$ is called nonexpansive if $H\left(T_{x}, T_{y}\right) \leq\|x-y\|$ for all $x, y \in D$. An element $p \in D$ is called a fixed point of $\mathrm{T}: \mathrm{D} \rightarrow \mathrm{D}$ (respectively, $\mathrm{T}: \mathrm{D} \rightarrow \mathrm{CB}(\mathrm{D})$ ) if $\mathrm{p}$ $=T_{p}$ (respectively, $p \in T_{p}$ ). The set of fixed points of $T$ is denoted by $\mathrm{F}(\mathrm{T})$. The mapping $\mathrm{T}: \mathrm{D} \rightarrow \mathrm{CB}(\mathrm{D})$ is called quasi-nonexpansive [1] if $\mathrm{F}(\mathrm{T}) \neq \varnothing$ and $\mathrm{H}\left(\mathrm{T}_{\mathrm{x}}, \mathrm{T}_{\mathrm{p}}\right) \leq \| \mathrm{x}$-p $\|$ for all $\mathrm{x} \in \mathrm{D}$ and all $\mathrm{p} \in \mathrm{F}(\mathrm{T})$. It is clear that every nonexpansive multi-valued mapping $\mathrm{T}$ with $\mathrm{F}(\mathrm{T}) \neq \varnothing$; is quasi-nonexpansive. But there exist quasi-nonexpansive mappings that are not nonexpansive (see [2]). It is known that if $\mathrm{T}$ is a quasi-nonexpansive multi-valued mapping, then $F(T)$ is closed.

Throughout this paper, we denote the weak convergence and the strong convergence by - and $\rightarrow$, respectively. The mapping $\mathrm{T}: \mathrm{D} \rightarrow \mathrm{CB}(\mathrm{D})$ is called hemicompact if, for any sequence $\left\{x_{n}\right\}$ in $D$ such that $d\left(x_{n}\right.$,
$\left.T x_{n}\right) \rightarrow 0$ as $n \rightarrow 1$, there exists a subsequence $\left\{x_{n k}\right\}$ of $\left\{x_{n}\right\}$ such that $x_{n k} \rightarrow p \in D$. We note that if $D$ is compact, then every multi-valued mapping $\mathrm{T}: \mathrm{D} \rightarrow \mathrm{CB}(\mathrm{D})$ is hemicompact.

A Banach space E is said to satisfy Opial's condition [3] if for each $\mathrm{x} \in \mathrm{E}$ and a sequence $\left\{\mathrm{x}_{\mathrm{n}}\right\}$ in $\mathrm{E}$ such that $\mathrm{x}_{\mathrm{n}} \rightarrow \mathrm{x}$, the following condition holds for all $\mathrm{x} \neq \mathrm{y}$ :

$$
\lim _{n \rightarrow \infty} \inf \left\|x_{n}-x\right\|<\lim _{n \rightarrow \infty} \inf \left\|x_{n}-y\right\|
$$

The mapping $\mathrm{T}: \mathrm{D} \rightarrow \mathrm{CB}(\mathrm{D})$ is called demi-closed if for every sequence $\left\{x_{n}\right\} \subset D$ and any $y_{n} \in T_{n}$ such that $x_{n}-x$ and $\mathrm{y}_{\mathrm{n}} \rightarrow \mathrm{y}$, we have $\mathrm{x} \in \mathrm{D}$ and $\mathrm{y} \in \mathrm{Tx}$.

Remark 1.1 ([4]). If the space $\mathrm{E}$ satisfies Opial's condition, then I-T is demi-closed at 0 , where $\mathrm{T}: \mathrm{D} \rightarrow \mathrm{K}(\mathrm{D})$ is a nonexpansive multi-valued mapping.

For a single-valued case, in 1953, Mann [5] introduced the following iterative procedure to approximate a fixed point of a nonexpansive mapping $\mathrm{T}$ in a real Hilbert space H:

$$
x_{n+1}=\alpha_{n} x_{n}+\left(1-\alpha_{n}\right) T x_{n}, \forall n \in \mathbb{N},
$$

where the initial point $x_{1}$ is taken in D arbitrarily and $\left\{\alpha_{n}\right\}$ is a sequence in $(0,1)$.

However, we note that Mann's iteration process (1.1) has only weak convergence, in general; for instance, see $[6,7,8]$.

Since 1953, Mann's iteration has extensively been studied by many authors (see, for examples, [9-18]). However, the studying of multivalued nonexpansive mappings is harder than that of single-valued nonexpansive mappings in both Hilbert spaces and Banach spaces.

The result of fixed points for multi-valued contractions and nonexpansive mappings by using the Hausdorff 
metric was initiated by Markin [19]. Later, different iterative processes have been used to approximate fixed points of multi-valued nonexpansive mappings (see also [1,20-26]).

In 2009, Song and Wang [26] proved strong and weak convergence theorems for Mann's iteration of a multivalued nonexpansive mapping $\mathrm{T}$ in a Banach space. They studied strong convergence of the modified Mann iteration which is independent of the implicit anchor-like continuous path $z_{t} \in t u+(1-t) T z_{t}$.

Let $\mathrm{D}$ be a nonempty and closed subset of a Banach space E, $\left\{\beta_{n}\right\} \subset[0,1],\left\{\alpha_{n}\right\} \subset[0,1]$ and $\left\{\gamma_{n}\right\} \subset(0,+\infty)$ such that $\lim _{n \rightarrow \infty} \gamma_{n}=0$.

(A) Choose $x_{0} \in \mathrm{D}$,

$$
x_{n+1}=\left(1-\alpha_{n}\right) x_{n}+\alpha_{n} \mathrm{y}_{n}, \forall n \geq 0,
$$

where $\mathrm{y}_{\mathrm{n}} \in \mathrm{Tx}_{\mathrm{n}}$ such that $\left\|\mathrm{y}_{\mathrm{n}+1}-\mathrm{y}_{\mathrm{n}}\right\| \leq \mathrm{H}\left(\mathrm{Tx}_{\mathrm{n}+1}, \mathrm{Tx}_{\mathrm{n}}\right)+\gamma_{\mathrm{n}}$.

(B) For fixed u $2 \mathrm{D}$, the sequence of modified Mann iteration is defined by $\mathrm{x}_{0} \in \mathrm{D}$,

$$
x_{n+1}=\beta_{n} u+\alpha_{n} x_{n+}\left(1-\alpha_{n}-\beta_{n}\right) \gamma_{n}+, \forall n \geq 0,
$$

where $\mathrm{y}_{\mathrm{n}} \in \operatorname{Tx}_{\mathrm{n}}$ such that $\left\|\mathrm{y}_{\mathrm{n}+1}-\mathrm{y}_{\mathrm{n}}\right\| \leq \mathrm{H}\left(\operatorname{Tx}_{\mathrm{n}+1}, \operatorname{Tx}_{\mathrm{n}}\right)+\gamma_{\mathrm{n}}$.

Very recently, Shahzad and Zegeye [2] obtained the strong convergence theorems for a quasi-nonexpansive multi-valued mapping. They relaxed the compactness of domain of $\mathrm{T}$ and constructed an iterative scheme which removes the restriction of $\mathrm{T}$ namely $\mathrm{T}_{\mathrm{p}}=\{\mathrm{p}\}$ for any $p \in F(T)$. The results provided an affirmative answer to some questions raised in [21]. In fact, they introduced iterations as follows:

Let $\mathrm{D}$ be a nonempty and convex subset of a Banach space $E$, let $T: D \rightarrow C B(D)$ and let $\left\{\alpha_{n}\right\},\left\{\alpha^{\prime}{ }_{n}\right\} \subset[0,1]$.

(C) The sequence of Ishikawa's iteration is defined by $\mathrm{x}_{0} \in \mathrm{D}$,

$$
\begin{aligned}
& y_{n}=\alpha_{n}^{\prime} z_{n}^{\prime}+\left(1-\alpha_{n}^{\prime}\right) x_{n}, \\
& x_{n+1}=\alpha_{n} z_{n}+\left(1-\alpha_{n}\right) x_{n}, \forall n \geq 0 .
\end{aligned}
$$

where $z_{n}^{\prime} \in T x_{n}$ and $z_{n} \in T y_{n}$.

(D) Let $\mathrm{T}: \mathrm{D} \rightarrow \mathrm{P}(\mathrm{D})$ and $\mathrm{P}_{\mathrm{T}} \mathrm{x}=\{\mathrm{y} \in \mathrm{Tx}:\|\mathrm{x}-\mathrm{y}\|=\mathrm{d}(\mathrm{x}, \mathrm{Tx})\}$, where $\mathrm{PT}$ is the best approximation operator. The sequence of Ishikawa's iteration [30] is defined by $\mathrm{x}_{0} \in \mathrm{D}$,

$$
\begin{aligned}
& y_{n}=\alpha_{n}^{\prime} z_{n}^{\prime}+\left(1-\alpha_{n}^{\prime}\right) x_{n}, \\
& x_{n+1}=\alpha_{n} z_{n}+\left(1-\alpha_{n}\right) x_{n}, \forall n \geq 0 .
\end{aligned}
$$

where $z_{n}^{\prime} \in \operatorname{Pr} x_{n}$ and $z_{n} \in \operatorname{Pr} y_{n}$.

It is remarked that Hussain and Khan [27], in 2003, employed the best approximation operator PT to study fixed points of *-nonexpansive multi-valued mapping $\mathrm{T}$ and strong convergence of its iterates to a fixed point of $\mathrm{T}$ defined on a closed and convex subset of a real Hilbert space.

Let $\mathrm{D}$ be a nonempty, closed and convex subset of a Banach space E. Let $\left\{T_{n}\right\}_{n=1}^{\infty}$ be a family of multi-valued mappings from $\mathrm{D}$ into $2^{\mathrm{D}}$ and let $\mathrm{P}_{\mathrm{Tn}} \mathrm{x}=\left\{\mathrm{y}_{\mathrm{n}} \in \mathrm{T}_{\mathrm{n}} \mathrm{x} \| \mathrm{x}-\right.$ $\left.\mathrm{y}_{\mathrm{n}} \|=\mathrm{d}\left(\mathrm{x}, \mathrm{T}_{\mathrm{n}} \mathrm{x}\right)\right\}, \mathrm{n} \geq 1$. Let $\left\{\alpha_{\mathrm{n}}\right\}$ be a sequence in $(0,1)$.
(E) The sequence of the modified Ishikawa's iteration is defined by $\mathrm{x}_{1} \in \mathrm{D}$ and

$$
x_{n+1} \in \alpha_{n} x_{n}+\left(1-\alpha_{n}\right) \operatorname{Pr} y_{n}, \forall n \geq 1,
$$

In this paper, we modify Mann's iteration by using the best approximation operator $\mathrm{P}_{\mathrm{Tn}}, \mathrm{n} \geq 1$ to find common fixed points of a countable family of nonexpansive multivalued mappings $\left\{T_{n}\right\}_{n=1}^{\infty}, n \geq 1$. Then we prove weak and strong convergence theorems for a countable family of multi-valued mappings in Banach spaces. Finally, we apply our main result to the problem of finding a common fixed point of a family of nonexpansive multi-valued mappings.

\section{Preliminaries}

In this section, we give some characterizations and properties of the metric projection in a real Hilbert space.

Let $\mathrm{H}$ be a real Hilbert space with inner product $<\cdot,>>$ and norm $\|\cdot\|$. Let $\mathrm{D}$ be a closed and convex subset of $\mathrm{H}$. If, for any point $\mathrm{x} 2 \mathrm{H}$, there exists a unique nearest point in $\mathrm{D}$, denoted by $\mathrm{P}_{\mathrm{D}} \mathrm{X}$, such that

$$
\left\|x-P_{D} x\right\| \leq\|x-y\|, \forall y \in D
$$

then $\mathrm{PD}$ is called the metric projection of $\mathrm{H}$ onto $\mathrm{D}$. We know that $\mathrm{PD}$ is a nonexpansive mapping of $\mathrm{H}$ onto $\mathrm{D}$.

Lemma 2.1 ([28]). Let D be a closed and convex subset of a real Hilbert space $\mathrm{H}$ and $\mathrm{PD}$ be the metric projection from $H$ onto $D$. Then, for any $x \in H$ and $z \in D, z=P D x$ if and only if the following holds:

$$
\langle x-z, y-z\rangle \leq 0, \forall y \in D
$$

Using the proof line in Lemma 3.1.3 of [28], we obtain the following result.

Proposition 2.2. Let $\mathrm{D}$ be a closed and convex subset of a real Hilbert space $H$. Let $T: D \rightarrow C C B(D)$ be a multivalued mapping and PT the best approximation operator. Then, for any $\mathrm{x} \in \mathrm{D}, \mathrm{z} \in \mathrm{P}_{\mathrm{T}} \mathrm{x}$ if and only if the following holds:

$$
\langle x-z, y-z\rangle \leq 0, \forall y \in T x
$$

Lemma 2.3 ([28]). Let $\mathrm{H}$ be a real Hilbert space. Then the following equations hold:

(1) $\|x-y\|^{2}=\|x\|^{2}-\|y\|^{2}-2\langle x-y, y\rangle$ for all $x, y \in H$;

(2) $\|t x+(1-t) y\|^{2}=t\|x\|^{2}+(1-t)\|y\|^{2}-t(1-t)\|x-y\|^{2}$

for all $t \in[0,1]$ and $x, y \in H$.

We next show that $\mathrm{P}_{\mathrm{T}}$ is nonexpansive under some suitable conditions imposed on $\mathrm{T}$.

Remark 2.4. Let $\mathrm{D}$ be a closed and convex subset of a real Hilbert space $H$. Let $T$ : $D \rightarrow C C B(D)$ be a multivalued mapping. If $\mathrm{Tx}=\mathrm{Ty}, \forall \mathrm{x}, \mathrm{y} \in \mathrm{D}$, then $\mathrm{P}_{\mathrm{T}}$ is $\mathrm{a}$ nonexpansive multi-valued mapping.

In fact, let $\mathrm{x}, \mathrm{y} \in \mathrm{D}$. For each $\mathrm{a} \in \mathrm{P}_{\mathrm{T}} \mathrm{x}$, we have

$$
d\left(a, \mathrm{P}_{T} y\right) \leq\|a-b\|, \forall b \in \mathrm{P}_{T} y
$$

From Proposition 2.2, we have

$\langle x-y-(a-b), a-b\rangle=\langle x-a, a-b\rangle+\langle y-b, b-a\rangle \geq 0$ 
It follows that

$$
\begin{aligned}
& \|a-b\|^{2}=\langle x-a, a-b\rangle+\langle a-b-(x-y), a-b\rangle \\
& \leq(x-y, a-b) \leq\|x-y\|\|a-b\|
\end{aligned}
$$

This implies that

$$
\|a-b\| \leq\|x-y\|
$$

From (2.1) and (2.3), we obtain

$$
d\left(a, P_{T} y\right) \leq\|x-y\|
$$

for every $\mathrm{a} \in \mathrm{P}_{\mathrm{T}} \mathrm{x}$. Hence $\sup _{a} \in P_{T} x d\left(a, P_{T} y\right) \leq\|x-y\|$. Similarly, we can show that $\sup _{b} \in P_{T} x d\left(P_{T} x, b\right) \leq\|x-y\| \quad$. $\quad$ Therefore $H\left(P_{T} x, P_{T} y\right) \leq\|x-y\|$.

It is clear that if a nonexpansive multi-valued mapping $\mathrm{T}$ satisfies the condition that $\mathrm{Tx}=\mathrm{Ty}, \forall \mathrm{x}, \mathrm{y} \in \mathrm{D}$, then PT is nonexpansive. The following example shows that if $\mathrm{T}$ is a nonexpansive multi-valued mapping satisfying the property that $\mathrm{Tx}=\mathrm{Ty}, \forall \mathrm{x}, \mathrm{y} \in \mathrm{D}$, then $\mathrm{Tx}$ is not $\mathrm{a}$ singleton for all $\mathrm{x} \in \mathrm{D}$.

\section{Strong and Weak Convergence of the Modified Ishikawa Iteration in Banach Spaces}

In this section, we first prove a strong convergence theorem for a countable family of multi-valued mappings under the SC-condition and Condition (A) and then prove a weak convergence theorem under the SC-condition in Banach spaces.

Theorem 3.1. Let D be a closed and convex subset of a uniformly convex Banach space E which satisfies Opial's condition. Let $\left\{\mathrm{T}_{\mathrm{n}}\right\}$ and $\tau$ be two families of multivalued mappings from D into $\mathrm{P}(\mathrm{D})$ with $\mathrm{F}(\tau)=\bigcap_{n=1}^{\infty} F\left(T_{n}\right) \neq \varnothing$. Let $\left\{\alpha_{n}\right\}$ be a sequence in $(0,1)$ such that 0 $0<\liminf _{n \rightarrow \infty} \alpha_{n} \leq \limsup _{n \rightarrow \infty} \alpha_{n}<1$. Let $\left\{\mathrm{x}_{n}\right\}$ be generated by (1.2). Assume that for

each $n \in \mathbb{N}, H\left(P_{T_{n}} x, P_{T_{n}} p\right) \leq\|x-p\|, \forall x \in D, p \in F(\tau) ;$

(A2) $\mathrm{I}-\mathrm{T}$ is demi-closed at 0 for all $\mathrm{T} \in \tau$.

If $\left\{T_{n}\right\}$ satisfies the SC-condition, then $\left\{x_{n}\right\}$ converges weakly to an element in $\mathrm{F}(\tau)$.

Proof. Since

$$
\begin{aligned}
& x_{n+1} \in \alpha_{n} x_{n}+\left(1-\alpha_{n}\right) P T_{n} y_{n} \\
& y_{n} \in \beta_{n} x_{n}+\left(1-\beta_{n}\right) P T_{n} x_{n}
\end{aligned}
$$

there exists $z_{n} \in P_{n} x_{n}, p \in F(\tau)$ and $n \in \mathbb{N}$. We note that $\mathrm{PT}_{\mathrm{n}} \mathrm{p}=\{\mathrm{p}\}$ for all. It follows from (A1) that

$$
\begin{aligned}
& \left\|y_{n}-p\right\|=\left\|\beta_{n} x_{n}+\left(1-\beta_{n}\right) P T_{n} x_{n}-P\right\| \\
& \leq \beta_{n}\left\|x_{n}-p\right\|+\left(1-\beta_{n}\right)\left\|P T_{n} x_{n}-P\right\| \\
& \leq \beta_{n}\left\|x_{n}-p\right\|+\left(1-\beta_{n}\right)\left\|z_{n}-P\right\| \\
& =\beta_{n}\left\|x_{n}-p\right\|+\left(1-\beta_{n}\right) d\left(z_{n}, P T_{n} p\right) \\
& \leq \beta_{n}\left\|x_{n}-p\right\|+\left(1-\beta_{n}\right) H\left(P T_{n} x_{n}, P T_{n} p\right) \\
& \leq \beta_{n}\left\|x_{n}-p\right\|+\left(1-\beta_{n}\right)\left\|x_{n}-P\right\| \leq\left\|x_{n}-P\right\|
\end{aligned}
$$

and Also

$$
\begin{aligned}
& \left\|x_{n+1}-P\right\|=\left\|a_{n} x_{n}+\left(1-\alpha_{n}\right) P T_{n} y_{n}-P\right\| \\
& =\left\|a_{n} x_{n}+\left(1-\alpha_{n}\right) P T_{n} y_{n}-\left(1-a_{n}+a_{n}\right) P\right\| \\
& \leq a_{n}\left\|x_{n}-P\right\|+\left(1-a_{n}\right)\left\|P T_{n} y_{n}-P\right\| \\
& \leq a_{n}\left\|x_{n}-P\right\|+\left(1-a_{n}\right) P T_{n}\left\|y_{n}-P\right\| \\
& \leq a_{n}\left\|x_{n}-P\right\|+\left(1-a_{n}\right) P T_{n}\left\|x_{n}-P\right\| \\
& \leq a_{n}\left\|x_{n}-P\right\|+\left(1-a_{n}\right)\left\|P T_{n} x_{n}-P\right\| \\
& \leq a_{n}\left\|x_{n}-P\right\|+\left(1-a_{n}\right)\left\|z_{n}-P\right\| \\
& =a_{n}\left\|x_{n}-P\right\|+\left(1-a_{n}\right) d\left(z_{n}, P T_{n} p\right) \\
& \leq a_{n}\left\|x_{n}-P\right\|+\left(1-a_{n}\right) H\left(P T_{n} x_{n}, P T_{n} p\right) \\
& \leq a_{n}\left\|x_{n}-P\right\|+\left(1-a_{n}\right)\left\|x_{n}-P\right\| \\
& \leq\left\|x_{n}-P\right\|
\end{aligned}
$$

for every $p \in F(T)$. Then $<\left\|x_{n}-p\right\|>$ is a decreasing sequence and hence $\lim _{n \rightarrow \infty}\left\|x_{n^{-}} p\right\|$ exists for every $p \in F(T)$. For $\mathrm{p} \in \mathrm{F}(\mathrm{T})$, since $\left\langle\mathrm{x}_{\mathrm{n}}>\right.$ and $<\mathrm{z}_{\mathrm{n}}>$ are bounded by Lemma 2.9, there exists a continuous, strictly increasing and convex function $g:[0,1) \rightarrow[0,1)$ with $g(0)=0$ such that

$$
\begin{aligned}
& \left\|y_{n}-P\right\|^{2}=\left\|\beta_{n}\left(x_{n}-p\right)+\left(1-\beta_{n}\right)\left(z_{n}-P\right)\right\|^{2} \\
& \leq \beta_{n}\left\|x_{n}-p\right\|^{2}+\left(1-\beta_{n}\right)\left\|z_{n}-P\right\|^{2} \\
& -\beta_{n}\left(1-\beta_{n}\right) g\left(\left\|x_{n}-z_{n}\right\|\right) \\
& \leq \beta_{n}\left\|x_{n}-p\right\|^{2}+\left(1-\beta_{n}\right) H\left(P T_{n} x_{n}, P T_{n} p\right) \\
& -\beta_{n}\left(1-\beta_{n}\right) g\left(\left\|x_{n}-z_{n}\right\|\right) \\
& \leq\left\|x_{n}-p\right\|^{2}-\beta_{n}\left(1-\beta_{n}\right) g\left(\left\|x_{n}-z_{n}\right\|\right)
\end{aligned}
$$

It follows that

$$
\beta_{n}\left(1-\beta_{n}\right) g\left(\left\|x_{n}-z_{n}\right\|\right) \leq\left\|x_{n}-p\right\|^{2}-\left\|y_{n}-p\right\|^{2}=0
$$

$$
\begin{gathered}
\underset{\text { Since }}{0<\liminf _{n \rightarrow \infty}} \lim _{n \rightarrow \infty}\left\|\mathrm{x}_{\mathrm{n}^{-}} \quad \mathrm{p}\right\| \quad \text { exists } \\
\limsup _{n \rightarrow \infty} g\left(\left\|x_{n}-z_{n}\right\|\right)=0
\end{gathered}
$$

By the properties of $g$, we can conclude that

$$
\lim _{n \rightarrow \infty}\left\|x_{n}-z_{n}\right\|=0
$$

Since $\left\langle\mathrm{T}_{\mathrm{n}}\right\rangle$ satisfies the SC-condition, there exists $\mathrm{C}_{\mathrm{n}} \in \mathrm{T}_{\mathrm{xn}}$ such that

$$
\lim _{n \rightarrow \infty}\left\|x_{n}-z_{n}\right\|=0
$$

for every $\mathrm{T} \in \tau$. Since $\left\langle\mathrm{X}_{\mathrm{n}}\right\rangle$ is bounded, there exists a subsequence $\left\langle\mathrm{x}_{\mathrm{nk}}\right\rangle$ of $\left\langle\mathrm{x}_{\mathrm{n}}\right\rangle$ converges weakly to some $\mathrm{q}_{1} \in \mathrm{D}$. It follows from (A2) and (3.3) that $\mathrm{q}_{1} \in \mathrm{Tq}_{1}$ for every $T \in \tau$. Next, we show that $\left\langle\mathrm{x}_{\mathrm{n}}\right\rangle$ converges weakly to $\mathrm{q} 1$, take another subsequence $\left\langle\mathrm{x}_{\mathrm{mk}}>\right.$ of $\left\langle\mathrm{x}_{\mathrm{n}}\right\rangle$ converging weakly to some $\mathrm{q}_{2} \in \mathrm{D}$. Again, as above we can conclude that $\mathrm{q}_{2} \in \mathrm{Tq}_{2}$ for every $\mathrm{T} \in \tau$. Finally, we show that $\mathrm{q}_{1}=\mathrm{q}_{2}$. Assume $\mathrm{q}_{1} \neq \mathrm{q}_{2}$. Then by Opial's condition of $\mathrm{E}$, we have

$$
\begin{aligned}
& \lim _{n \rightarrow \infty}\left\|x_{n}-q_{1}\right\|=\lim _{k \rightarrow \infty}\left\|x_{n k}-q_{1}\right\|<\lim _{k \rightarrow \infty}\left\|x_{n k}-q_{2}\right\| \\
& =\lim _{n \rightarrow \infty}\left\|x_{n}-q_{2}\right\|=\lim _{k \rightarrow \infty}\left\|x_{m k}-q_{2}\right\| \\
& <\lim _{k \rightarrow \infty}\left\|x_{m k}-q_{1}\right\|=\lim _{n \rightarrow \infty}\left\|x_{n}-q_{1}\right\|
\end{aligned}
$$


which is a contradiction. Therefore $q_{1}=q_{2}$. This shows that $<\mathrm{X}_{\mathrm{n}}>$ converges weakly to a fixed point of $\tau$ for every $\mathrm{T} \in \tau$. This completes the proof.

Corollary 3.2. Let D be a closed and convex subset of a uniformly convex Banach space $E$ which satisfies Opial's condition. Let $\left\{T_{n}\right\}$ and $\tau$ be two families of nonexpansive multivalued mappings from $\mathrm{D}$ into $\mathrm{K}(\mathrm{D})$ with $\mathrm{F}(\tau)=\bigcap_{n=1}^{\infty} F\left(T_{n}\right) \neq \varnothing$. Let $\left\{\alpha_{n}\right\}$ be a sequence in $(0,1)$ such that $0<\liminf _{n \rightarrow \infty} \alpha_{n} \leq \limsup _{n \rightarrow \infty} \alpha_{n}<1$. Let $\left\{x_{n}\right\}$ be generated by (1.2). Assume that for each $n \in \mathbb{N}$,

$$
H\left(P_{T_{n}} x, P_{T_{n}} p\right) \leq\|x-p\|
$$

$\forall \mathrm{x} \in \mathrm{D}, \mathrm{p} \in \mathrm{F}(\tau)$. If $\left\{\mathrm{T}_{\mathrm{n}}\right\}$ satisfies the SC-condition, then $\left\{x_{n}\right\}$ converges weakly to an element in $F(\tau)$.

Theorem 3.3. Let D be a closed and convex subset of a uniformly convex Banach space E which satisfies Opial's condition. Let $\left\{\mathrm{T}_{\mathrm{n}}\right\}$ and $\tau$ be two families of multivalued mappings from D into $\mathrm{P}(\mathrm{D})$ with $\mathrm{F}(\tau)=\bigcap_{n=1}^{\infty} F\left(T_{n}\right) \neq \varnothing$. Let $\left\{\alpha_{n}\right\}$ be a sequence in $(0,1)$ such that 0 $0<\liminf _{n \rightarrow \infty} \alpha_{n} \leq \limsup _{n \rightarrow \infty} \alpha_{n}<1$. Let $\left\{\mathrm{x}_{n}\right\}$ be generated by (1.2). Assume that for each $n \in \mathbb{N}, H\left(P_{T_{n}} x, P_{T_{n}} p\right) \leq\|x-p\|, \forall x \in D, p \in F(\tau) ;$

(B2) the best approximation operator $\mathrm{P}_{\mathrm{T}}$ is nonexpansive for every $\mathrm{T} \in \tau$;

(B3) $F(\tau)$ is closed.

If $\left\{T_{n}\right\}$ satisfies the SC-condition and Condition (A), then fxng converges strongly to an element in $F(\tau)$.

Proof. It follows from the proof of Theorem 3.1 that $\lim _{n \rightarrow \infty}\left\|x_{n}-p\right\|$ exists for every $p \in \mathrm{F}(\tau)$ and $\lim _{n \rightarrow \infty}\left\|x_{n}-z_{n}\right\|$ where $z_{n} \in P_{T_{n}} x_{n}$. Since fTng satisfies the SC- condition, there exists $C_{n} \in \operatorname{Tx}_{n}$ such that

$$
\lim _{n \rightarrow \infty}\left\|x_{n}-c_{n}\right\|=0
$$

for every $\mathrm{T} \in \tau$. This implies that

$$
\lim _{n \rightarrow \infty} d\left(x_{n}, T x_{n}\right) \leq \lim _{n \rightarrow \infty} d\left(x_{n}, P_{T} x_{n}\right)<\lim _{n \rightarrow \infty}\left\|x_{n}-c_{n}\right\|=0
$$

for every $T \in \tau$. Since that $\left\{T_{n}\right\}$ satisfies Condition (A), we have $\lim _{n \rightarrow \infty} d\left(x_{n}, F(\tau)\right)=0$.

It follows from (B3), there is subsequence $\left\{x_{n_{k}}\right\}$ of $\left\{x_{n}\right\}$ and a sequence $\left\{p_{k}\right\} \subset F(\tau)$ such that

$$
\left\|x_{n_{k}}-p_{k}\right\|<\frac{1}{2^{k}}
$$

for all k. From (3.1), we obtain

$$
\begin{aligned}
\left\|x_{n_{k+1}}-p\right\| & \leq\left\|x_{n_{k+1}-1}-p\right\| \\
& \leq\left\|x_{n_{k+1}-2}-p\right\| \\
& \vdots \\
& \leq\left\|x_{n_{k}}-p\right\|
\end{aligned}
$$

for all $p \in F(\tau)$. This implies that

$$
\left\|x_{n_{k+1}-1}-p_{k}\right\| \leq\left\|x_{n_{k}}-p_{k}\right\|<\frac{1}{2^{k}}
$$

Next, we show that $\left\{p_{k}\right\}$ is a Cauchy sequence in D. From (3.4) and (3.5), we have

$$
\begin{aligned}
& \left\|p_{k+1}-p_{k}\right\| \leq\left\|p_{k}\right\| \\
& \leq\left\|p_{k+1}-x_{n_{k+1}}\right\|+\left\|x_{n_{k+1}}-p_{k}\right\| \leq \frac{1}{2^{k-1}}
\end{aligned}
$$

This implies that $\left\{\mathrm{p}_{\mathrm{k}}\right\}$ is a Cauchy sequence in $\mathrm{D}$ and thus converges to $q \in D$. Since PT is nonexpansive for every $\mathrm{T} \in \tau$,

$$
d\left(p_{k}, T q\right) \leq d\left(p_{k}, P_{T} q\right) \leq H\left(P_{T} p_{k}, P_{T} q\right) \leq\left\|p_{k}-q\right\|(3.7)
$$

for every $T \in \tau$. It follows that $d(q, T q)=0$ for every $T \in \tau$ and thus $\mathrm{q} \in \mathrm{F}(\tau)$. It implies by (3.4) that $\left\{\mathrm{x}_{\mathrm{nk}}\right\}$ converges strongly to q. Since $\lim _{n \rightarrow \infty}\left\|x_{n}-q\right\|$ exists, it follows that $\left\{x_{n}\right\}$ converges strongly to $q$. This completes the proof.

We know that if $\mathrm{T}$ is a quasi nonexpansive multivalued mapping, then $F(T)$ is closed. So we have the following result:

Corollary 3.4. Let D be a closed and convex subset of a uniformly convex Banach space E. Let $\left\{\mathrm{T}_{\mathrm{n}}\right\}$ and $\tau$ be two families of nonexpansive multivalued mappings from D into P(D) with $\mathrm{F}(\tau)=\bigcap_{n=1}^{\infty} F\left(T_{n}\right) \neq \varnothing$. Let $\left\{\alpha_{n}\right\}$ be a sequence in $(0,1)$ such that $0<\liminf _{n \rightarrow \infty} \alpha_{n} \leq \limsup _{n \rightarrow \infty} \alpha_{n}<1$. Let $\left\{\mathrm{x}_{n}\right\}$ be generated by (1.2). Assume that for each $n \in \mathbb{N}, H\left(P_{T_{n}} x, P_{T_{n}} p\right) \leq\|x-p\|, \forall x \in D, p \in F(\tau)$ and the best approximation operator $\mathrm{P}_{\mathrm{T}}$ is nonexpansive for every $\mathrm{T} \in \tau$.

If $\left\{T_{n}\right\}$ satisfies the SC-condition and Condition (A), then $\left\{x_{n}\right\}$ converges strongly to an element in $F(\tau)$.

\section{References}

[1] C. Shiau, K.K. Tan, C.S. Wong, Quasi-nonexpansive multi-valued maps and selection, Fund. Math. 87 (1975) 109-119.

[2] N. Shahzad, H. Zegeye, On Mann and Ishikawa iteration schemes for multivalued maps in Banach spaces, Nonlinear Anal. 71 (2009) 838-844.

[3] Z. Opial, Weak convergence of the sequence of successive approximations for nonexpansive mappings, Bull. Am. Math. Soc. 73 (1967) 591-597.

[4] E.L. Dozo, Multivalued nonexpansive mappings and Opials condition, Proc. Am. Math. Soc. 38 (1973) 286-292.

[5] W.R. Mann, Mean value methods in iteration, Proc. Am. Math. Soc. 4 (1953) 506-510.

[6] H.H. Bauschke, E. Matouskova, S. Reich, Projection and proximal point methods: convergence results and counterexamples, Nonlinear Anal. 56 (2004) 715-738.

[7] A. Genal, J. Lindenstrass, An example concerning fixed points, Israel J.Math. 22 (1975) 81-86.

[8] S. Reich, Weak convergence theorems for nonexpansive mappings in Banach spaces, J. Math. Anal. Appl. 67 (1979) 274-276.

[9] D. Boonchari, S. Saejung, Construction of common fixed points of a countable family of -demicontractive mapping in arbitrary Banach spaces, Appl. Math. Comput. 216 (2010) 173-178.

[10] P. Cholamjiak, S. Suantai, Weak convergence theorems for a countable family of strict pseudocontractions in Banach spaces, Fixed Point Theory Appl., Vol. 2010, Article ID 632137, 16 pages.

[11] Y.J. Cho, S.M. Kang, H. Zhou, Some conditions on iterative methods, Commun. Appl. Nonlinear Anal. 12 (2005) 27-34. 
[12] S. Itoh, W. Takahashi, Singlevalued mappings, multivalued mappings and fixed point theorems, J. Math. Anal. Appl. 59 (1977) 514-521.

[13] W.A. Kirk, Transfinite methods in metric fixed point theory, Abstr. Appl. Anal. 5 (2003) 311-324.

[14] T.C. Lim, Remarks on some fixed point theorems, Proc. Am. Math. Soc. 60 (1976) 179-182.

[15] N. Shioji, W. Takahashi, Strong convergence of approximated sequences for nonexpansive mappings in Banach spaces, Proc. Am. Math. Soc. 125 (1997) 3641-3645.

[16] Y. Song, On a Mann type implicit iteration processes for continuous pseudo-contractive mappings, Nonlinear Anal. 67 (2007) 3058-3063.

[17] Y. Song, S. Hu, Strong convergence theorems for nonexpansive semigroup in Banach spaces, J. Math. Anal. Appl. 338 (2008) 152161.

[18] T. Suzuki, Strong convergence theorems for infinite families of nonexpansive mappings in general Banach space, Fixed Point Theory Appl. 1 (2005) 103-123.

[19] J.T. Markin, Continuous dependence of fixed point sets, Proc. Am. Math. Soc. 38 (1973) 545-547.

[20] M. Abbas, S.H. Khan, A.R. Khan, R.P. Agarwal, Common fixed points of two multivalued nonexpansive mappings by one-step iterative scheme, Appl. Math. Lett. 24 (2011) 97-102.

[21] B. Panyanak, Mann and Ishikawa iterative processes for multivalued mappings in Banach spaces, Comput. Math. Appl. 54 (2007) 872-877.

[22] D.R. Sahu, Strong convergence theorems for nonexpansive type and non-self multi- valued mappings, Nonlinear Anal. 37 (1999) 401-407.
[23] K.P.R. Sastry, G.V.R. Babu, Convergence of Ishikawa iterates for a multivalued map-pings with a fixed point, Czechoslovak Math. J. 55 (2005) 817-826.

[24] Y. Song, H. Wang, Erratum to Mann and Ishikawa iterative processes for multivalued mappings in Banach spaces [Comput. Math. Appl. 54 (2007) 872-877]. Comput. Math. Appl. 55 (2008) 2999-3002.

[25] Y. Song, Y.J. Cho, Iterative approximations for multivalued nonexpansive mappings in reexive Banach spaces, Math. Ineq. Appl. 12 (3) (2009) 611-624.

[26] Y. Song, H. Wang, Convergence of iterative algorithms for multivalued mappings in Banach spaces, Nonlinear Anal. 70 (2009) 1547-1556.

[27] N. Hussain, A.R. Khan, Applications of the best approximation operator to *- nonexpansive maps in Hilbert spaces, Numer. Funct. Anal. Optim. 24 (2003) 327-338.

[28] W. Takahashi, Nonlinear Functional Analysis: Fixed Point Theory and its Applications, Yokohama Publishers, Yokohama, 2000. 10 Poonam Lata Sagar and S.K. Malhotra

[29] K. Nakajo, K. Shimoji, W. Takahashi, Strong convergence to common fixed points of families of nonexpansive mappings in Banach spaces, J. Nonlinear and Convex Anal. 8 (2007) 11-34.

[30] S. Ishikawa, Fixed points by a new iteration method, Proc. Am. Math. Soc. 44 (1974) 147-150.

[31] H.K. Xu, Inequalities in Banach spaces with applications, Nonlinear Anal. 16 (1991) 1127-1138.

[32] W. Cholamjiak, S. Suantai,Weak and strong convergence theorems for a _nite family of generalized asymptotically quasinonexpansive mappings, Comput. Math. Appl. 60 (2010) 19171923. 